\title{
News and Events
}

\section{IUCEE News and Updates}

\section{Program Updates:}

- IIEECP Teacher Certification Course: The IIEECP Certification Program for 2016-17 has been revised based on the experiences from the three Pilots conducted in 2015-16. Phase I has been offered at seven different locations all over India during May- August, 2016. Phase II is currently being offered, September - December 2016 with Phase III planned in January 2017. Several other Phase I workshops and Institutional Certifications are planned for the rest of the year. The revised version is expected to lead to financial sustainability as well as significant scale-up. A collection of short video clips by faculty who have gone through this program is being prepared in order to showcase the benefits.

- IUCEE Virtual Academy:Some of the users of National Instruments tools have been sharing their experiences of successful implementation in their curriculum. The attendance and response has been very good. Readers of JEET are encouraged to consider offering webinars of their recent work related to engineering education. It is very easy. A 10 minute practice session will be offered to those interested. For any additional information about any of the above please send email to Sridhar Nori, Manager IUCEE Virtual Academy, sridharn18@gmail.com

- IUCEE Outstanding Engineering Educator Awardsare being instituted for educators who have made outstanding contribution to the teaching-learning process in engineering education. The awards will be given out during the Fourth International Conference on Transformations in Engineering Education (ICTIEE 2017). 66 nominations have been received andbeing reviewed by a panel of global experts in engineering education. Awards will be presented at one of the three locations of ICTIEE 2017 (Hyderabad on Jan 8, Rajkot on Jan 10 and Jaipur on Jan 12), as convenient to the Awardee.

- IUCEE Gurukuls for Learning and Outcomes Based Education (IGLOBE) meet on-line every two weeks to continue progress towards institutional transformations. Four themes are being emphasized, based on the collective discussions at the First Gurukul Summit held July 28, 29 at KLE Technological University, Hubbali, Karnataka. The four themes are Outcomes Based Education, Engineering Education Research Culture, Institutional Strategic Planning and Building Industry-Academy Partnerships.

- IUCEE-EPICS Partnership has six institutions working on adapting the EPICS (Engineering Projects in Community Service) program of Purdue University, USA with the help of biweekly meetings including Prof. Oakes of Purdue University. 


\section{News and Events}

- Industry Teaching Fellows, a group of experienced engineers from industry, meet regularly to guide IUCEE regarding industry-academy partnerships with a focus on employability of engineering graduates.

\section{Upcoming Conferences}

- WEEF and GEDC 2016: The World Engineering Education Forum 2016, Global Engineering Deans Council 2016 as well as the Global Student Forum will be held together in Seoul, Korea from November 6-10, 2016. Details are at: http://www.weef-gedc2016.org/.

- ICTIEE 2017: The Fourth International Conference on Transformations in Engineering Education, co-organized by IUCEE, will be held at three locations: Jan 6-8, 2017 at Vardhaman College of Engineering, Hyderabad, Jan 9-10, 2017 at R.K. University, Rajkot and Jan 11-12, 2017 at Manipal University Jaipur. Please visit website for information and Call for Papers : http://www.ictiee.org/

Formoreinformation about any of these, pleaseemailKrishna_Vedula@uml.edu) 


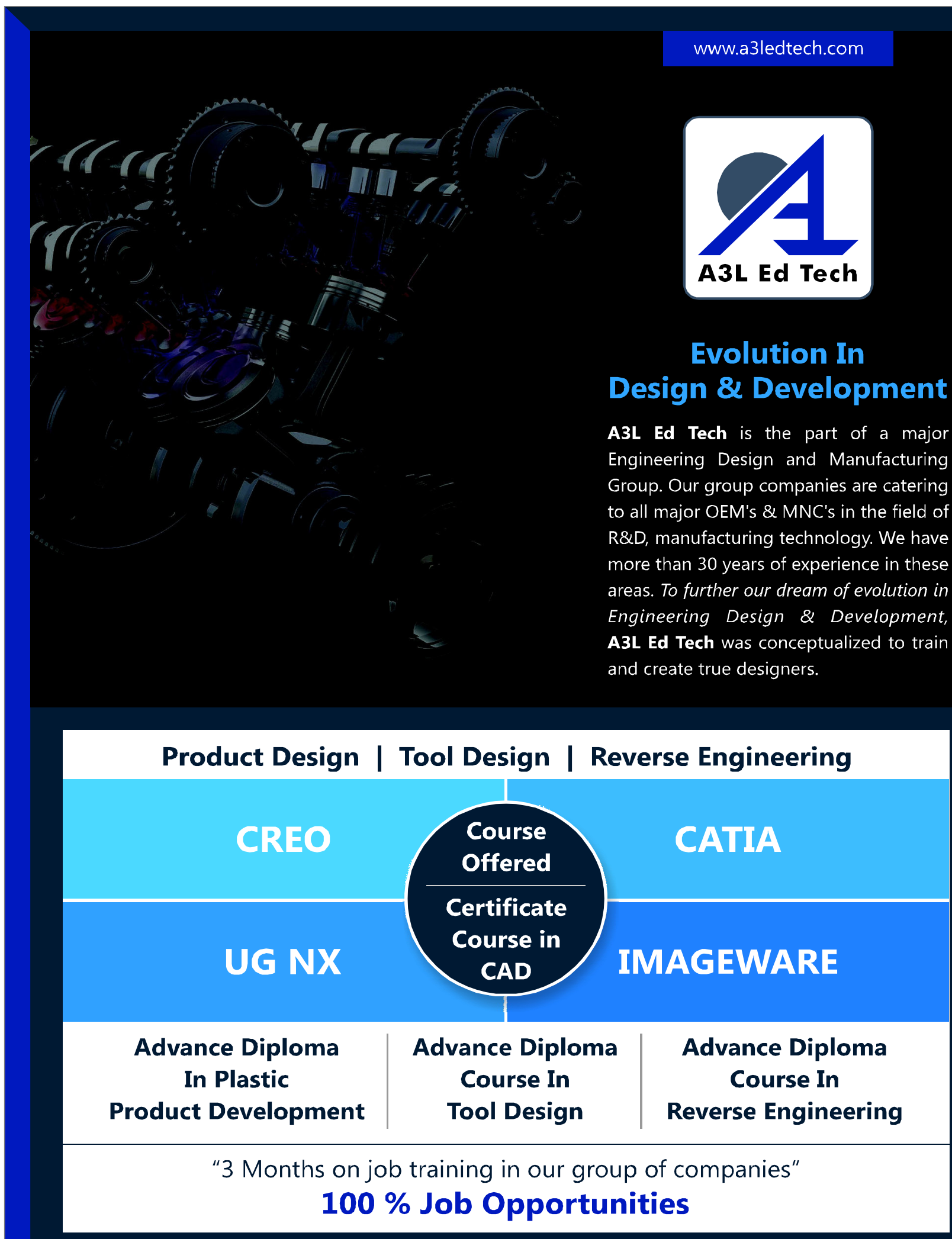

ADMISSIONS OPEN
A3L Ed Tech 302A, Om Chambers, Third Floor, Above Panchali Hotel, Jangali Maharaj Road, Shivaji Nagar, Pune, Maharashtra, India.

E020-30276316 | +919890362558 | +919209016166 